(6) OPEN ACCESS

1 Oncology, Johns Hopkins School of Medicine, Baltimore, Maryland, USA

${ }^{2}$ Pediatrics, Johns Hopkins School of Medicine, Baltimore, Maryland, USA

${ }^{3}$ Dermatology, Johns Hopkins School of Medicine, Baltimore, Maryland, USA

\section{Correspondence to Dr Elias T Zambidis, ezambid1@jhmi.edu}

Accepted 16 February 2018

Check for updates

To cite: Cuviello A, Rice J, Cohen B, et al. BMJ Case Rep Published Online First: [please include Day Month Year]. doi:10.1136/bcr-2018224506

\title{
Infant with a skin lesion and respiratory distress
}

\author{
Andrea Cuviello, ${ }^{1}$ Jessica Rice, ${ }^{2}$ Bernard Cohen, ${ }^{3}$ Elias T Zambidis ${ }^{1,2}$
}

\section{DESCRIPTION}

A 2-month-old full-term male infant presented with worsening tachypnoea and a rapidly enlarging, smooth-topped, infiltrative, bronze-yellow nodule with overlying telangiectasias on the mid-sternum (figure 1A). CT imaging demonstrated multiple pulmonary nodules, and enhancing extradural masses compressing the L4-L5 vertebral neural foramina. Immunohistochemical staining of biopsies from skin and pulmonary lesions demonstrated a highly proliferative histiocytosis (figure 1B), which was positively immunoreactive for ALK (anaplastic lymphoma kinase) (figure 1C), CD33 and factor XIIIa, weakly positive for CD68, and negative for CD1a, Langerin, CD34, CD20, CD3, CD43, SOX10, S100, C-KIT, lysozyme and myeloperoxidase. These findings were consistent with a diagnosis of ALK + histiocytosis with pathological features of juvenile xanthogranulomatosis (JXG). Whole body MRI and positron emission tomography (PET)/ CT imaging (figure 2) confirmed that the extensive pulmonary and compressing spinal cord lesions were fluorodeoxyglucose (FDG)-avid, and further revealed an additional, metabolically active right meningeal/parietal parenchymal brain tumour and extensive mediastinal/abdominal lymphadenopathy. Flourescence in situ hybridization (FISH) and DNA mutation sequencing of the histiocytomas revealed a translocated KIF5B-ALK fusion rearrangement. Together, these findings revealed that this was a rare case of systemic non-Langerhans ALK+ JXG with central nervous system (CNS) involvement ( $\sim 1 \%-2 \%$ of cases), which has been reported to be associated with significant morbidity and mortality. ${ }^{1}$

Langerhans cell histiocytosis (LCH) and JXG are rare histiocytic disorders with clinically variable neoplastic behaviours and are characterised by a clonal proliferation of cells of the monocyte-dendritic lineage. The majority $(\sim 80 \%)$ of JXG cases present with solitary skin lesions, and can be managed with conservative observation or surgical resection, if cosmetically desired. ${ }^{1}$ Chemotherapy (eg, corticosteroids and vinca alkaloids) or low-dose radiation therapy has also been employed with success. ${ }^{2}$ The ALK-KIF5B fusion is a known oncogenic activating mutation and is frequently identified in lung adenocarcinoma and anaplastic lymphomas. ${ }^{3}$ ALK-KIF5B fusions are rare in histiocytic disorders and have been reported in only a handful of cases. The presence of aberrant ALK + genomic lesions may define a clinically distinct class of aggressive non-Langerhans histiocytic disorders. ${ }^{3}{ }^{4}$ The role and long-term efficacy of targeted ALK inhibitor (eg, crizotinib) therapies in the treatment of ALK+ histiocytic disorders currently remain unknown, but potentially beneficial.
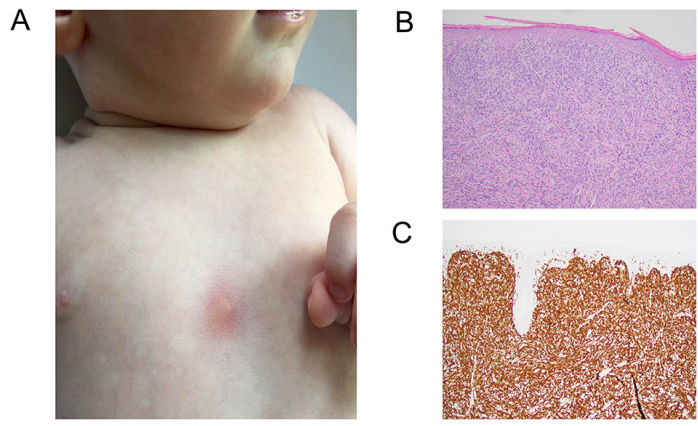

Figure 1 (A) The presenting primary skin lesion with an erythematous base and raised yellow discoloured central region characteristic of juvenile xanthogranulomas.

(B) H\&E and (C) anaplastic lymphoma kinase antigen immunostaining of dermal lesion.

Given the known aggressive nature of ALK mutations in other neoplastic disorders and the presence of systemic and CNS disease in this patient, chemotherapy was initiated with the purine analogue cladribine (2-CDA; 2 -chlorodeoxyadenosine). This drug was chosen based on established efficacy in the treatment of adult and paediatric multifocal, systemic LCH and JXG with CNS involvement. ${ }^{12}$ Follow-up PET imaging after six cycles of 2-CDA therapy demonstrated a near-complete resolution of all FDG-avid lesions. The patient was subsequently started on low-dose daily 6-mercaptupurine and weekly methotrexate maintenance

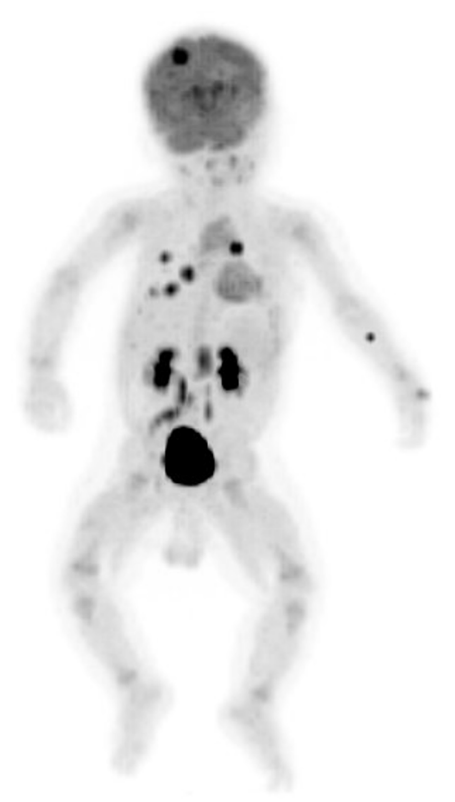

Figure 2 Whole body positron emission tomography image demonstrating systemic, multifocal disease with involvement of lungs, brain, vertebrae and lymph nodes. 


\section{Patient's perspective}

"Getting the proper diagnosis for our infant son was a long and winding road. It took multiple scans, specialists, and procedures before we had a name for his rare disorder and an understanding of its extent. Being told there were only three other known cases was a shock and of little comfort. There was no clear path forward or expert consensus on what treatment to pursue, and being such a rare disease, it was difficult to find reliable information and support. We were lucky to have physicians who listened to us and were able to understand his subtle symptoms, and pursue appropriate imaging and thorough testing. Because of this, our son received prompt and effective chemotherapy and is growing and thriving today."

\section{Learning points}

Systemic ALK+ histiocytosis involving the CNS is a rare disorder, potentially associated with significant morbidity and mortality; the presence of oncogenic ALK (anaplastic lymphoma kinase) mutations in systemic-CNS histiocytosis may portend an inherently unpredictable, aggressive course.

- Treatment with cladribine (2-CDA) provides welltolerated and potent therapeutic responses in systemic histiocytic disorders involving the CNS, including juvenile xanthogranulomatosis.

- ALK inhibitors may represent an alternative form of targeted molecular therapy for ALK+ histiocytic disorders. However, further investigation of the durability of such targeted therapy is warranted. chemotherapy, and currently remains in remission of disease on follow-up radiological imaging. This case represents a rare case of a haematological disorder with potentially broad implications for the understanding and targeted therapy of other ALK-positive malignancies.

Contributors AC, JR, BC and ETZ performed history and examination, acquired diagnostic data and studies, prepared the manuscript and images, and reviewed the literature. AC and ETZ designed the treatment plan. AC, JR, BC and ETZ wrote and edited the manuscript, and prepared the learning points. ETZ prepared the final version and approval of the manuscript.

Funding This work was supported by grants from NIH/NEI (R01EY023962) and NIH/NICHD (R01HD082098).

Competing interests None declared.

Patient consent Parental/guardian consent obtained.

Provenance and peer review Not commissioned; externally peer reviewed.

Open Access This is an Open Access article distributed in accordance with the Creative Commons Attribution Non Commercial (CC BY-NC 4.0) license, which permits others to distribute, remix, adapt, build upon this work non-commercially, and license their derivative works on different terms, provided the original work is properly cited and the use is non-commercial. See: http://creativecommons.org/ licenses/by-nc/4.0/

(c) BMJ Publishing Group Ltd (unless otherwise stated in the text of the article) 2018. All rights reserved. No commercial use is permitted unless otherwise expressly granted.

\section{REFERENCES}

1 Rajendra B, Duncan A, Parslew R, et al. Successful treatment of central nervous system juvenile xanthogranulomatosis with cladribine. Pediatr Blood Cancer 2009;52:413-5.

2 Stover DG, Alapati S, Regueira 0, et al. Treatment of juvenile xanthogranuloma. Pediatr Blood Cancer 2008;51:130-3.

3 Chan JK, Lamant L, Algar E, et al. ALK+ histiocytosis: a novel type of systemic histiocytic proliferative disorder of early infancy. Blood 2008;112:2965-8.

4 Lee LH, Gasilina A, Roychoudhury J, et al. Real-time genomic profiling of histiocytoses identifies early-kinase domain BRAF alterations while improving treatment outcomes. JCI Insight 2017;2:e89473.

Copyright 2018 BMJ Publishing Group. All rights reserved. For permission to reuse any of this content visit

http://group.bmj.com/group/rights-licensing/permissions.

BMJ Case Report Fellows may re-use this article for personal use and teaching without any further permission.

Become a Fellow of BMJ Case Reports today and you can:

- Submit as many cases as you like

- Enjoy fast sympathetic peer review and rapid publication of accepted articles

- Access all the published articles

- Re-use any of the published material for personal use and teaching without further permission

For information on Institutional Fellowships contact consortiasales@bmjgroup.com

Visit casereports.bmj.com for more articles like this and to become a Fellow 